\title{
The present situation analysis on humanized management in Lijiang first class hotels
}

\author{
Yu Shanshan ${ }^{a}$, Li Yan ${ }^{b}$ \\ Tourism and Culture College of Yunnan University, 674100 \\ a79603085 @qq.com, b360385476@qq.com
}

Keywords: First class hotels, Humanized management, Lijiang

\begin{abstract}
With the rapid development of Lijiang tourism, hotel industry there also exposed some problems. A serious problem is the relationship between employee turnover and humanized management. Lijiang first class hotels are mostly international hotels and domestic national hotels. By comparing studies of humanized management in these hotels, both types of hotel management have strengths, but it is still a long way to go before establishing a perfect humanized management.
\end{abstract}

\section{Introduction}

Lijiang is China's major tourist destination. Lijiang tourism has developed rapidly in recent years. A total of tourists home and abroad in Lijiang in 2012 was 15.99 million, and the tourism revenue was 21.173 billion RMB. In this context, Lijiang first class hotel industry is also developing rapidly. Since the first listed five-star hotel opened in 1998, there has been more than ten listed five-star or international affiliated high-grade hotel business in Lijiang, and there are several hotels built and ready for use. With the gradually fierce high-level competition among Lijiang hotel industry, all sorts of problems also begin to expose. Among them, a more prominent problem is higher hotel staff turnover. Lower employee stability makes hotels spend more on human resource management, which directly affect hotel development. And humanized management situation of hotel has direct and close contact with employee turnover. This article analyzes the relationship between staff loyalty, agreement and hotel management methods through investigation and study of several representative high star hotels in Lijiang from the perspectives of humanized management to find out the humanized degree of first class hotel management methods.

\section{Research Method}

Lijiang first class hotels can be divided into international affiliated and local national brand hotel two kinds. This article selected two representative hotels in each type, which means four hotels were taken as research objects. There are three main data sources: first, referred to hotel's historical data, and collected 43 pieces (sets) various data; Second, did questionnaire survey of grassroots employees on a wide range. A total of 166 effective questionnaires were taken back. Third, interviewed mid-level managers, and interviewed management people 21 times.

The so-called humanized management is to build scientific and effective management methods, pay attention to the all-round development of people, motivate and develop the advantages of humanity, eliminate and suppress the weakness of human nature, and establish a unique human-oriented corporate culture [1]. Its specific contents include: effective material incentive and spiritual incentive, humanized salary system, provide a variety of development opportunities for staff, help employees to develop career planning, and paying attention to win-win strategy of enterprises and individuals [2]. Humanized management in this article is mainly analyzed in five aspects: Whether the hotel offers good personal development opportunities for staff, including training opportunities and promotion space; Whether employees have self-assessment, effort and reward recognition; Whether employees are trust; Whether humanized measures are in the system implementation; How the circumstances of organized recreational activities of the enterprise are. 
Finally grade the above several aspects according to the 5 standard qualitative evaluations: outstanding, good, general, poor, very poor.

\section{The Humanized Management Features of International Affiliated Hotels}

\section{A. Personal development opportunity}

The management of international affiliate hotel staff's personal development is good.

On one hand, in order to improve the comprehensive quality of employees, hotels will organize all kinds of trainings. These trainings include a variety of skills and training, orientation, organization skills contest, online courses for all employees, and employ relevant personage for hotel lectures, etc.; Hotels send employees to get off-job training, which is more short-term training geared to the needs of senior leaders and some good employees, such as international hotel's headquarters training, or related enterprise organization learning in other cities. Although there are many types of training, the difference between actual effects is bigger. Skills training is more emphasized because it involves employees' daily work and business level. Instead, the cultural quality training such as public class is of the suspicion of only existence both the leadership and ordinary employees' attention degree are not high.

On the other hand, while all the international affiliated hotels establish clear life career planning for employees, some workers do not recognize the feasibility of its implementation, and the main differences lie in the examination cycle.

Let's take the just graduate student entering the hotel industry as a waiter at the grass-roots level. Most of the employees think that they have improved their personal ability largely, and can cope with various situations after working for a year and a half or so. In the questionnaire of waiters at the grass-roots level, nearly $80 \%$ of employees think this job "buried their talents", and only less than $10 \%$ of the employees think the work "made the best they could." So grass-roots employees want to get promotion after working about a year and a half. If they cannot reach this goal, employees will choose to leave. On the contrary, hotel thinks the basic study and exercise time should be two years or longer for grass-roots staff just coming into hotel industry. In interview, all mid-level managers regard that an employee can properly handle all kinds of situations after at least two years of continuous learning and exercise. But the reality is, the international affiliated employed staff is from all over the country, and the hotel staff's city identity is not strong, which forms obvious difference from Lijiang local hotel. Sometimes in order to keep good employees, hotel will shorten the promotion period to meet the requirements of employees. This kind of practice for managers might be a bit out of helpless, but it gets some employees' agreement at the grass-roots level.

B. Employees' self-assessment effort and reward ratio

In the questionnaire of international affiliated hotels grassroots employees, as much as $96 \%$ of workers say "their reward is far behind effort", and only less than $4 \%$ of the employees think "their return and pay are the same”. It shows that employees are more discontent about hotel employee's strength and stringent requirements and think their salary is low. In interview, some mid-level managers also admitted that Lijiang hotel industry wages have lagged behind other industries, and eventually lead to many employees to get to other industries, and further exacerbate staff turnover in hospitality industry.

\section{Employees trust}

In international affiliated hotel employees shows a tendency of polarization in trust evaluation.

On the one hand, in order to ensure that service quality conforms to the requirements of hotel headquarters, international affiliated hotels build system of investigations. Hotel headquarters will implicitly assign relevant staff to pretend customers coming to subordinates and hotel service. After finding the problem, hotel headquarters will issue notices. The advantages of this system are to facilitate hotel management, the crosswise comparison between hotels, and easy assessment of hotel staff. But this system also has obvious disadvantages, which is the subordinate hotel managers; especially senior managers will feel not trusted. 
Hotels, on the other hand, in order to improve the degree of humanized management, also give some power to employees at all levels from the top managers of disposition, to single free, discount or small gift to the customer. This makes the grass-roots staff feel satisfied in the hotel because of the trust.

D. Human nature in system implementation

In the interview, most employees reflect the hotel is too strict during execution. Such as hotel staff will be punished at guest complaints, and some of the complaints and event processing are not the responsibility of the employees. When this happens, the punishment may make the staff feel wronged and not understand, and think the hotel is impersonal while conducting punishment without analysis of specific situation. Because of the unified management of all hotels under international affiliated hotels, this kind of phenomenon is relatively common, and also one of the main factors of poor humanized management evaluating international affiliated employees.

E. Enterprise organized recreational activities

Enterprise cultural activities can not only cultivate staff team cooperation ability, improve staff competitive consciousness, show other aspects ability, and help staff development in an all-round way. More importantly, recreational activities can relieve the strain of employee work atmosphere, ease the relationship between the managers and employees, harmonize the relationship between colleagues, and it is an important part of humanistic management. 94\% of respondents in international affiliated hotels said that there are less hotel recreational activities organization and can't come up to the expectations of employees and the demand of humanized management. This is mainly because hotel managers don't know fully the significance of cultural activities and role, do not take enterprise culture construction, and there are several senior managers who think little importance of organizing recreational activities for managing employees.

\section{Humanized Management Characteristics of Local National Hotel Brand}

\section{A. Personal development opportunity}

Personal development is relatively slow in the local national hotel brand.

Training, Lijiang local national brand hotel for staff training is mainly within the hotel orientation, basic skills training, etc. These trainings mainly fuse at work, and training difficulty is not high. The employees awareness only stays in learning skills, at the same time, hotels rarely have the opportunity to lead the staff to go out training and learning, so this kind of training has limited improvement capacity for employees as a whole.

Compared with international affiliated hotels, domestic national brand hotels staff assessment and promotion period is longer. There are many employees have more than 4 years at grass-roots level. This characteristic has two kinds of tendency for employees' performance: although the non-local employees or younger employees have lower hotel's loyalty, and are more inclined to leave the place or leave the hotel to work in other hotels. But for local grassroots employees from Lijiang, the identity of the city is very high, and the tendency of departure is not very strong, so they can accept a longer working in the same hotel. Some older official would always work in the same hotel. While hotel recruiting talents, they also prefer to hire local residents rather than high degree other city's college students.

B. Employee self-assessment's effort and reward ratio

Hotel choses more cautious promotion staff with full considerations of the employee's personal assessment and expectations. In the survey, although there are still 54\% grassroots employees think "their reward is far behind effort", but it is better than $96 \%$ international affiliated hotels. In another analysis, nearly half of all employees think they are engaged in work "make his best". That of international affiliated hotels is less than $10 \%$, and the local national brand hotel employees get more recognition.

C. Employees trust degree

Local national hotel brand has complete independent management and no headquarters regulation in international hotel management system, so its degree of freedom is larger. All business strategy 
and supervision are implemented by hotel internally. Leaders at all levels are mostly older employees promoted hotel internally. Some senior leaders have worked more than 10 years in the hotel. The hotel has a reason to trust employees and full empowerment. Most of the employees think that they are highly trusted by the hotel.

D. Humanized system implementation

Local national brand hotel system implementation is relatively flexible, which is generally believed that the employees' human nature is higher. A senior executive in the interview said he worked for several hotels, both international affiliated hotels and local national brand hotels. He feels the big difference is in flexibility of system implementation. Local hotel staff had more chances to contact boss. While encounter problems, they can more fully analyze the specific circumstances of processing and solve it, so its management methods also have won the acceptance of employees. This training part directly cultivates the employee loyalty to the hotel. When some employees are asked why they won't move to the international hotel, their answer is that the hotel working environment is looser and less constraint.

E. Enterprise organized recreational activities

In order to unite workers, enterprises organize recreational activities combined with actual situation. Leaders are more concerned about the construction of enterprise culture, so the recreational activities of its organization are relatively more than that of international hotel, but it still cannot meet employees' psychological expectations.

\section{Two Types of Hotel Management Mode}

Table 1: Lijiang two kinds of hotels' humanized management comparison

\begin{tabular}{|l|l|l|}
\hline & International hotel & Domestic national brand hotel \\
\hline Personal development opportunities & good & poor \\
\hline $\begin{array}{l}\text { Employee self-evaluation effort and } \\
\text { reward ratio }\end{array}$ & Very poor & general \\
\hline Employees trust degree & general & good \\
\hline $\begin{array}{l}\text { System implementation } \\
\text { humanization }\end{array}$ & Very poor & good \\
\hline $\begin{array}{l}\text { Enterprise organized recreational } \\
\text { activities }\end{array}$ & poor & general \\
\hline
\end{tabular}

A. Advantages and disadvantages analysis of international hotel management mode

International hotel management system pays more attention to rigid implementation and stronger means.

The advantages of this management mode have the following several aspects. First, standardized management. Hotel wants unified management mode, and carries on relatively clear crosswise comparison in order to ensure all aspects test of the hotel. Second, service standardization. Any hotel wants consumers to enter any company owned by the hotel, which is relatively stable and have high service level, and establish a good corporate image in consumers' mind. Through the recognition of corporate image, ultimately influence and guide the behavior of consumers when choosing a hotel.

The disadvantages of international affiliate hotel management patterns are more obvious. First, they cannot adapt to the changing social and cultural environment. After transplanting from elsewhere to Lijiang, the management experience would not necessarily adapt to local social and cultural environment, and results in cross-cultural conflict problems. If hotel can't coordinate well, this will lead to employees' resistance because of different understanding. Second, affect the initiative of employees. Whether trust degree or employee self-evaluation are low, this affects employees' work enthusiasm and initiative, and too strict and impersonal system can make employees have more "no gains, no faults" idea, which would affect hotel operation.

B. Advantages and disadvantages of analysis on humanized management mode of local national hotel brand

Native brand enterprise management mode, by contrast, is on the basis of the system, which increases more humanized management. Its advantages lie in: first, effectively motivate the 
employees. Give employees full trust, and when problems arise, analyze the specific issues and let employees accept more, which also let employees more positive in work performance. Second, it is suitable for local customs. Lijiang local hotel roots in local culture, local residents are mostly from the management to grass-roots staff with more convenient communication with each other, and would not cause different cultural barriers due to cultural background.

But domestic hotel management mode also has its weaknesses: first, the management efficiency is not high. Local hotel depends more on people management. It's easy to have a case by case. Second, management method is not stable. Different ways on same nature of the same old thing, which would easily let the employees misunderstand and think unfair. Third, it depends on managers' preferences. Hotel's rules and regulations are set by top managers, which inevitably reflect managers' preferences, at the same time, the success or failure of hotel development is directly related to enterprise managers' experience, quality, and character. If enterprise managers are outstanding entrepreneurs, they can keep calm at any time. The enterprise system making and system execution must be helpful for the long-term development of the enterprise; but if the entrepreneur quality itself is not enough, it is easy to produce relatively big errors of administration.

\section{Recommendations and Conclusions}

First, strengthen humanized management consciousness of middle managers. In interview, we find that Lijiang international hotel's middle-level managers have not clear and incorrect phenomenon understanding of humanized management. Some senior managers made it clear that employees' disapproval of enterprises come largely from its direct leadership's disapproval. If hotel middle managers cannot be very good to carry out humanized management, it will cause great influence to hotel management.

Second, based on rigid system, the management of human nature is strengthened. The international and native Lijiang hotel management methods have advantages and disadvantages. The hotels need to complement each other, on the basis of rigid system construction, with humanized implementation, eventually achieve optimal management effect.

If Lijiang international hotel wants further development, humanized management upgrade is imperative from rigid institutionalized management, but humanized management level of Lijiang hotels is relatively backward, and it is still a long way to go before truly achieving the level of humanized management.

\section{References}

[1] Zhou Ying. Build mechanism of mental health [J]. Journal of Talent Development, 2010, (7) : $44 \sim 45$

[2] Gao Ang. Employees "happiness" is not a dream [J]. Journal of Human Resources, 2010, (12) : 32 $\sim 33$ 